\title{
Complexity Analysis of a Four-Dimensional Energy-Economy-Environment Dynamic System
}

\author{
Shuai Jin ${ }^{1}$ and Liuwei Zhao $\mathbb{D}^{1,2}$ \\ ${ }^{1}$ School of Management, Jiangsu University, Zhenjiang, Jiangsu 212013, China \\ ${ }^{2}$ School of Business, Jiangsu University of Technology, Changzhou, Jiangsu 213001, China \\ Correspondence should be addressed to Liuwei Zhao; 136901672@qq.com
}

Received 16 June 2020; Revised 7 August 2020; Accepted 11 August 2020; Published 27 August 2020

Academic Editor: Viorel-Puiu Paun

Copyright (c) 2020 Shuai Jin and Liuwei Zhao. This is an open access article distributed under the Creative Commons Attribution License, which permits unrestricted use, distribution, and reproduction in any medium, provided the original work is properly cited.

A novel four-dimensional energy, economic, and environmental (3E) under energy reduction constraints chaotic system is proposed. The acquisition of environmental quality data is the key to this paper. During the course of the study, we used Bayesian estimation algorithm to calibrate the environmental quality. Based on the official data, the Levenberg-Marquardt backpropagation neural network method was optimized by genetic algorithm to effectively identify the parameters in the $3 \mathrm{E}$ system. The research results show that although increasing energy reduction inputs can improve environmental quality, the effect on energy intensity and overall stability of the system is not obvious. When polluting input in the ecological environment system affects its maximum capacity, the environmental system collapses (i.e., the ecological system can no longer purify the environment through the self-circulation process and will eventually die out). Therefore, it is necessary to correctly grasp the ecological environment protection and the relationship between economic developments and explore synergies to promote ecological priorities and green development new ideas.

\section{Introduction}

In the context of the rapid development of the global economy, China has become one of the largest economy groups; however, there are obvious contradictions between rapid economic growth with energy use and the protection of the environment. There are mutual influences and mutual checks and balances among energy systems, economic systems, and environmental systems. Therefore, to achieve coordinated development of energy, economic, and environmental system has become an important part of achieving development goals of the region. Economy-energy-environment system has come into being $3 \mathrm{E}$ system, which is used for analyzing the comprehensive development level of economy, energy, and environment for a region, thus using the result data to judge the degree of coordination among economy, energy, and environment and make a new plan.

New elements have been continuously created as the evolution of $3 \mathrm{E}$ systems has not followed the linear mechanism, which has made the world even more diversified and complicated. Thus, it is fair to say that the nonlinear evolution model has become the prerequisite that has gradually enriched and complicated the $3 \mathrm{E}$ system. It is the new elements coming from the nonlinear mechanism that has supported the evolution and complicated the elements. Accordingly, the information that follows suits has continued to increase and accumulate, which has ensured the sustainable development. The complicated nonlinear mechanism generally lies in the elements outside and inside of the environment system, which has stabilized the structure, organization, and the conditioning mechanism for the system, to stimulate and confine the revolution of the whole system.

Presently, we have seen massive research on nonlinear model's complexity. For instance, Zhao et al. believe that there are many species in the environmental system; there are complex relationships among species, such as parasitism, symbiosis, and natural enemies. There are direct or indirect connections among all species, which constitute a complex ecological network. Because the environmental system has the characteristics of nonlinearity, self-organization, 
nonnegotiability, dynamics, openness, multilevel, self-similarity, and so on, it is a typical complex system, and it is a large system with many elements, levels, and complex relationships. If we want to solve the current environmental problems facing mankind, we must apply complexity theory to environmental problems making the structure of environmental system more reasonable and the balance of environment, economy, and society rebuilt [1]. Fang believes that structural complexity is one of the most fundamental problems of dynamic complexity of ecosystems. The development and application of dynamic system theory are helpful to understand the complexity of ecosystem. It is pointed out that structural complexity and dynamic complexity are interrelated. Simple dynamic models of ecosystem show that simple structural systems can produce very complex and unpredictable dynamic behavior in some cases. However, the ecosystems with complex structures may not necessarily produce complex dynamic behaviors [2]. Development and application of the dynamics system would help enhance the understanding of 3E system's complexity. The research would also help indicate that complexity between structure and dynamics are interrelated. The 3E system's simple dynamic model indicated that simple structure system would generate complicated and unpredictable dynamic behavior. However, the complied ecosystem would not necessarily lead to complicated dynamic behavior [3]. We can make basic judgment on current researches on 3E system's internal connectivity and interaction from multiple perspectives. Some of the researches are based on the samples from the time series and applied from cointegration and causal tests, discussing the relationship between energy and economy. Scholars all around the world have consensus about the interaction of the two, believing that consumption of energy and economic growth has been highly correlated for the long time and yet exhibits notable regional difference $[4,5]$. Regarding the relationship between energy and environment, some scholars believe that increase in energy output and consumption are the main culprit behind the degradation of environment $[6,7]$. It is worth noting that most of the researches on the topic are based on Kuznets curve, while the conclusions that follow suit are divergent. On the one hand, the supporters aim to figure out the internal motivations [8-10] that form the EKC from the perspective of economic growth, trade, and policies. They have come to the roughly similar conclusion: the quality of environment would be improved in tandem with economic development following its degradation. On the other hand, the skeptics of the EKC believe that the relationship between economy and environment could include U-shape, N-shape, or synchronous curves [11-13].

Some other researches are based on the comprehensive discussion regarding the $3 \mathrm{E}$ system. However, the scholars have chosen different research timing and methods, mainly including measurement and evaluation of the $3 \mathrm{E}$ system's coordination [14], application of dynamic CGE model [15], the endogenous growth model [16], and the relationships and correlations among outputs of $3 \mathrm{E}$ based on the analysis of the econometric model [17]. Current literature has basic consensus of the conclusion regarding the coordination analysis of the $3 \mathrm{E}$ system, believing that China's coordination remains at a lower level. Meanwhile, Wei et al. have included demographic system into their researches, leading to a dynamically open yet more complicated system, in order to build up multipurpose planning and an integrated model reflecting a check-and-balance relationship [18]. The research comes with a novel angel.

Currently, environmental protection still falls behind social and economic development. Pollutions caused by multistages, multifields, and multitypes have been continually mounting, yet the environmental carrying capacity has (nearly) reached its limit. Hence, the worsening environmental problems have not been radically resolved. In the process of handling the issues, people have been gradually aware that improvement of the environmental quality hinges on well-managed resources, resolved environmental problems, and control of pollutants' emission. Good environmental quality is related to the sustainable development of the economy and society. It is an important breakthrough to adjust the economic structure and achieve economic growth. It is conducive to promoting economic competition and promoting the development of green development and environmental industries. Accordingly, various scholars have embarked on research on energy reduction. For instance, Löschel and Otto have built up a dynamic balance model to study the relationships among the variables including carbon dioxide emission, energy consumption, speed of technological innovation, and economic development. His conclusion suggests that decision-makers prudently design the carbon dioxide emission cut policies [19]. Erdmenger and his team detailed the measures for Germany to reach its $\mathrm{CO}_{2}$ emission target by $40 \%$ and carbon emission cut by $224 \mathrm{mn}$ MT [20]. Xu and his team adopt the AIM and CGE models to evaluate sulfur dioxide control's impact on the pollutant and $\mathrm{CO}_{2}$ emission cut locally. They believe that China could enjoy the benefits from carbon emission via control over sulfur dioxide emission [21]. Cullende and Allood found through research that efficiency is a very important role in carbon emission reduction. The scale of the energy flow is an important indicator to evaluate potential return from the efficiency. Estimating the global energy flow's scale and complexity could bring about the maximum energy efficiency return [22]. Prasad studied the impact of renewable energy policies in 39 states on $\mathrm{CO}_{2}$ reduction. They discovered that, after 19 states' introduction of Fund for the Public Interest, or something similar to "carbon tax," $\mathrm{CO}_{2}$ emission has seen notable and stable decline [23]. Fang established a three-dimensional system for energy conservation and emission reduction and obtained energy-saving attractions. Meanwhile, they evaluate the performance of energy saving and emission cut [24-27]; more research is needed [28, 29].

In recent years, BP neural network has attracted more and more attention in the field of artificial intelligence. Many nonlinear methods have been proposed to predict the trend of energy and economy, such as BP neural network [30-34]. BP neural network has unique advantages in economic fields such as economic analysis [35-38] and time series prediction. If the computation amount allows, any number of many-to-many mappings can be fitted with a smaller fitting error. The strong coupling relationship among the factors in the prediction system 
is an interwoven and interactive relationship, which can be expressed by the connection weights and thresholds between nodes in each layer. Compared with the traditional multiple regression prediction method, this expression has better fitting ability and precision. BP neural network has strong nonlinear function approximation ability and has been widely used in time series analysis and financial forecasting. BP neural network has the ability to fit the function and determine the weights and thresholds between neurons through learning process [39]. Therefore, we depended on the official statistics and measured data of the China Statistical Yearbook to predict the future trend of $3 \mathrm{E}$.

In the process of enhancing environment governance, we have seen more complicated environmental issues for which it is more difficult to find solutions. With that, we see even more difficulties and complexity for the various projects to further strengthen environment governance and environmental quality improvement. Presently, industrialization, urbanization, and modernization have propelled energy demand at a growth stage. Ongoing consumption increase in fossil fuels with high pollution and high carbon emission has impeded the sustainable development for the environment. Therefore, we need to fully realize the dynamic complexity of the $3 \mathrm{E}$ system and the lag of environmental protection, in order to reduce the damage more effectively and rationally to the ecological environment system and make the economy sustainable.

With the rapid development of environmental protection, the gradual improvement of social-environmental awareness, and the increasing competition in the industry, the environmental governance network is a complex adaptive system formed by the game and interest coordination and self-organization under the market operation mechanism. Therefore, the research on $3 \mathrm{E}$ systems needs to pay more attention to the complexity brought by multisystem interaction. In general, $3 \mathrm{E}$ is increasingly showing the dynamic complexity of the system. Therefore, it is necessary to study how the three systems of the main body establish an effective coordination strategy mechanism and study the environmental governance network and economy based on such microbehavior and game characteristics. Develop a macrointegrated structure and a mechanism for the formation of good performance, in particular, the emergence of the overall structure and performance of $3 \mathrm{E}$ systems and the systematic analysis between environmental and economic systems. In the meantime, judging from the current research that concerns the impact of environmental governance and environmental governance system engineering and diving deeply into current study, we believe that the following aspects need to be enhanced and perfected. Study the following issues: First, based on the research foundation of the relationship of the dual systems, we need to integrate the $3 \mathrm{E}$ into the system analysis, by developing theoretical analyses based on the multiple systems' coordination and development angles. Secondly, we need to study the evaluation pattern of the 3E's complexity. Thirdly, the official data are used to identify the $3 \mathrm{E}$ system parameters and the evolution of the $3 \mathrm{E}$ system analyzed. It is under such current situation that the $3 \mathrm{E}$ system's variation pattern would be of significance to the system's sustainable development.
This study makes a series of significant contributions to the research of the 3E's complexity:

First, this study considers the inclusion of energy reduction constraints on the $3 \mathrm{E}$ system proposed and gets a new four-dimensional system, which is more in line with the actual situation and the current development needs. Second, this study deviates from the leading research on energy-economy-environment systems research that focuses primarily on environmental impact analysis [40], global environmental development [41], eco-industrial systems planning $[42,43]$, dynamic assessment of urban economy-resource-environment systems [44], and economic and environmentally sustainable development [45]. Here, through the stability analysis of dynamic 3E system by system complexity theory, the gap in methodology commonly used in $3 \mathrm{E}$ system research is bridged. The results provide a practical policy prescription for effective pollution control.

Third, based on the official data, the Levenberg-Marquardt backpropagation neural network method was optimized by genetic algorithm to effectively identify the parameters in the $3 \mathrm{E}$ system, which is more conducive to better research on the interaction between various elements of the $3 \mathrm{E}$ system.

This paper is organized as follows. In Section 2, we construct a $3 \mathrm{E}$ system with energy-constrained constraints and theoretically analyze the system through the theory of complexity and use numerical simulation to demonstrate the various dynamic behaviors of the four-dimensional system. In Section 3, the genetic algorithm is used to optimize the LM-BP neural network method to identify and confirm the system parameters of the four-dimensional system. In Section 4, an indepth analysis of the changes in key parameters of the system is carried out to study the stability and dynamic complexity of the system. Finally, the main conclusions of this study are given.

\section{Model Construct and Theoretical Analysis}

2.1. Model Construct. In the paper, we consider the inclusion of energy reduction constraints on the $3 \mathrm{E}$ system proposed by Zhao et al. [1] and get a new four-dimensional system, which is more in line with the actual situation and the current development needs. Energy, economy, and environment (3E) system containing energy reduction constraints is given in the following form:

$$
\left\{\begin{array}{l}
\dot{x}=a_{1} x\left(\frac{y}{M-1}\right)-a_{2} y+a_{3} z+a_{4} w \\
\dot{y}=-b_{1} x+b_{2} y\left(\frac{1-y}{F}\right)+b_{3} z\left(\frac{1-z}{E}\right)-b_{4} w \\
\dot{z}=c_{1} x\left(\frac{x}{N-1}\right)-c_{2} y-c_{3} z-c_{4} w \\
\dot{w}=d_{1} x-d_{2} y+d_{3} z\left(\frac{1-z}{H}\right)+d_{4} w\left(\frac{y}{P-1}\right),
\end{array}\right.
$$


where $x(t), y(t), z(t)$, are $w(t)$, respectively, the level of energy conservation and emission reduction, pollution emission, economic growth (GDP), and environmental quality in period $t, a_{i}, b_{i}, c_{i}, d_{i}(i=1,2,3,4), M, F, E, N, H$, and $P$ are normal numbers, $t \in I$, and $I$ is an economic cycle. (Table 1)

In system (1), $\dot{x}$ represents the change level of energy saving and emission reduction in $t$ period; $\dot{y}$ represents the level of change in pollution emissions in $t$ period; $\dot{z}$ represents the growth level of economic growth in the $t$ period; $\dot{w}$ represents the change level of environmental quality in $t$ period. When the impact of pollution exceeds the maximum capacity of the ecological environment (that $\dot{w}>0$ ), it means that the ecological environment is deteriorating. In this case, the ecosystem cannot rely on self-regulation to repair. Therefore, when this situation continues, the ecological environment will eventually be sold out; when $\dot{w} \leq 0$, it means that the environmental quality has reached a dynamic balance or gradually improved, and only under this condition can the ecological environment be the basis of human social development [46-48].

By system (1), energy intensity can be launched; the form of energy intensity is as follows:

$$
\text { energy intensity }=\frac{\text { A economic cycle energy consumption }}{\text { GDP within an economic cycle }} \text {. }
$$

Next, we will analyze the dynamics of $3 \mathrm{E}$ system containing energy reduction constraints. By calculation, the Jacobian matrix of the system (1) can be obtained as follows:

$$
J=\left[\begin{array}{cccc}
\left(\frac{y}{M}-1\right) a_{1} & \frac{x a_{1}}{M}-a_{2} & a_{3} & a_{4} \\
-b_{1} & \frac{(F-2 y) b_{2}}{F} & \frac{(E-2 z) b_{3}}{E} & -b_{4} \\
-\frac{(N-2 x) c_{1}}{N} & -c_{2} & -c_{3} & -c_{4} \\
d_{1} & -d_{2}+\frac{w d_{4}}{P} \frac{(H-2 z) d_{3}}{H}\left(\frac{y}{P-1}-1\right) d_{4}
\end{array}\right]
$$

The six real equilibrium points of the $3 \mathrm{E}$ system (1) are, respectively, $\quad O(0,0,0,0), \quad S_{1}\left(x_{1}, y_{1}, z_{1}, w_{1}\right)$, $S_{2}\left(x_{2}, y_{2}, z_{2}, w_{2}\right), S_{3}\left(x_{3}, y_{3}, z_{3}, w_{3}\right), S_{4}\left(x_{4}, y_{4}, z_{4}, w_{4}\right)$, and $S_{5}\left(x_{5}, y_{5}, z_{5}, w_{5}\right)$. The Jacobian matrix of system (1) at equilibrium point $O(0,0,0,0)$ is of the following form:

$$
J_{0}=\left[\begin{array}{cccc}
-a_{1} & -a_{2} & a_{3} & a_{4} \\
-b_{1} & b_{2} & b_{3} & -b_{4} \\
-c_{1} & -c_{2} & -c_{3} & -c_{4} \\
d_{1} & -d_{2} & d_{3} & -d_{4}
\end{array}\right] .
$$

So the characteristic polynomial of $J(O)$ is as follows:

$$
f(\lambda)=\lambda^{4}+A \lambda^{3}+B \lambda^{2}+C \lambda+D=0,
$$

where

$$
\begin{aligned}
A= & a_{1}-b_{2}+c_{3}+d_{4}, \\
B= & a_{3} c_{1}-a_{2} b_{1}+b_{3} c_{2}-b_{2} c_{3}-a_{4} d_{1}+b_{4} d_{2}+c_{4} d_{3}-b_{2} d_{4}+c_{3} d_{4}+a_{1}\left(c_{3}+d_{4}-b_{2}\right), \\
C= & a_{1} b_{3} c_{2}-a_{1} b_{2} c_{3}+a_{4} b_{2} d_{1}-a_{4} c_{3} d_{1}-a_{4} b_{1} d_{2}+a_{1} b_{4} d_{2}+b_{4} c_{3} d_{2}-b_{3} c_{4} d_{2} \\
& +a_{4} c_{1} d_{3}+b_{4} c_{2} d_{3}+a_{1} c_{4} d_{3}-b_{2} c_{4} d_{3}-a_{1} b_{2} d_{4}+b_{3} c_{2} d_{4}+a_{1} c_{3} d_{4}-b_{2} c_{3} d_{4} \\
& +a_{3}\left(c_{4} d_{1}+c_{1} d_{4}-b_{2} c_{1}-b_{1} c_{2}\right)-a_{2}\left(b_{3} c_{1}-b_{4} d_{1}+b_{1}\left(c_{3}+d_{4}\right)\right), \\
D= & a_{2} b_{4} c_{3} d_{1}-a_{2} b_{3} c_{4} d_{1}+a_{1} b_{4} c_{3} d_{2}-a_{1} b_{3} c_{4} d_{2}-a_{2} b_{4} c_{1} d_{3}+a_{1} b_{4} c_{2} d_{3}-a_{2} b_{1} c_{4} d_{3}-a_{1} b_{2} c_{4} d_{3} \\
& -a_{4}\left(b_{3} c_{2} d_{1}-b_{2} c_{3} d_{1}+b_{3} c_{1} d_{2}+b_{1} c_{3} d_{2}+b_{2} c_{1} d_{3}+b_{1} c_{2} d_{3}\right)-a_{2} b 3 c_{1} d_{4}+a_{1} b_{3} c_{2} d_{4} \\
& -a 2 b_{1} c_{3} d_{4}-a_{1} b_{2} c_{3} d_{4}+a_{3}\left(b_{4} c_{2} d_{1}-b_{2} c_{4} d_{1}+b_{4} c_{1} d_{2}+b_{1} c_{4} d_{2}-b_{2} c_{1} d_{4}-b_{1} c_{2} d_{4}\right) .
\end{aligned}
$$

System (1) is a very complex dynamic system, when $a_{i}, b_{i}$, $c_{i}, d_{i}, M, F, E, N, H$, and $P$ values are different, system (1) performance is complex, and dynamic behavior is also different. In this study, we set the following: $a_{1}=0.09$, $a_{2}=0.025, a_{3}=0.012, a_{4}=0.165, b_{1}=0.422, \quad b_{2}=0.2$, $b_{3}=0.8, \quad b_{4}=0.4, \quad c_{1}=0.035, \quad c_{2}=0.008, \quad c_{3}=0.075$, $c_{4}=0.078, d_{1}=0.121, d_{2}=0.035, d_{3}=0.0145, d_{4}=0.775$, $M=0.9, F=1.6, E=2.95, N=0.35, H=1.25$, and $P=2.4$.

By calculation, four eigenvalues of the Jacobian matrix $J(O) \quad$ are $\quad \lambda_{1}=0.2236, \quad \lambda_{2}=-0.7845, \quad$ and $\lambda_{3,4}=-0.0895 \pm 0.0706 i$. Because $\lambda_{i}<1(i=1,2,3,4)$, we know that the equilibrium $O(0,0,0,0)$ is unstable.
Let $c_{2}$ be any value, so we can obtain the following characteristic equation:

$$
\begin{aligned}
f(\lambda)= & \lambda^{4}+0.74 \lambda^{3}+\left(0.8 c_{2}-0.0683\right) \lambda^{2} \\
& +\left(0.6927 c_{2}-0.0297\right) \lambda-0.0026+0.036 c_{2}=0 .
\end{aligned}
$$

Let

$$
p_{1}=0.74
$$

$p_{2}=0.8 c_{2}-0.0683$, $p_{3}=0.6927 c_{2}-0.0297, \quad$ and $\quad p_{4}=0.036 c_{2}-0.0026$. According to the Routh-Hurwitz criterion, we can obtain the following conditions: $p_{1}=0.74>0, \quad p_{1} p_{2}-p_{3}>0$, and $p_{1} p_{2} p_{3}-p_{4} p_{1}^{2}-p_{3}^{2}>0$. By calculation, when 
TABle 1: The specific meanings of each parameter are explained.

\begin{tabular}{|c|c|}
\hline Parameter & Explanation $(t \in I, I$ is an economic cycle) \\
\hline$a_{1}$ & The development coefficient of energy saving and emission reduction $x(t)$ \\
\hline$a_{2}$ & The inhibition coefficient of pollution emission $y(t)$ on energy saving and emission reduction $x(t)$ \\
\hline$a_{3}$ & The influence coefficient of $z(t)$ input of economic growth on energy saving and emission reduction $x(t)$ \\
\hline$a_{4}$ & The influence coefficient of $w(t)$ input of environmental quality on energy saving and emission reduction $x(t)$ \\
\hline$b_{1}$ & The influence coefficient of the development of energy saving and emission reduction $x(t)$ on pollution emission $y(t)$ \\
\hline$b_{2}$ & The development rate elasticity coefficient of pollution emission $y(t)$ \\
\hline$b_{3}$ & The influence coefficient of economic growth $z(t)$ on pollution emission $y(t)$ \\
\hline$b_{4}$ & The inhibition coefficient of environmental quality $w(t)$ on pollution emission $y(t)$ \\
\hline$c_{1}$ & The influence coefficient of the development of energy saving and emission reduction $x(t)$ on economic growth \\
\hline$c_{2}$ & The influence coefficient of pollution emission $y(t)$ on economic growth $z(t)$ \\
\hline$c_{3}$ & The restraint factor of investment in energy saving and emission reduction $x(t)$ on economic growth $z(t)$ \\
\hline$c_{4}$ & The restraint factor of investment in improving environmental quality $w(t)$ on economic growth $z(t)$ \\
\hline$d_{1}$ & $\begin{array}{c}\text { The influence coefficient of the development of energy saving and emission reduction } x(t) \text { on the improvement of } \\
\text { environmental quality } w(t)\end{array}$ \\
\hline$d_{2}$ & The inhibition coefficient of pollution emission $y(t)$ on environmental quality $w(t)$ \\
\hline$d_{3}$ & The influence coefficient of economic growth $z(t)$ 's investment on improving environmental quality $w(t)$ \\
\hline$d_{4}$ & The speed coefficient of ecological environment self-repair without external intervention \\
\hline$M$ & The peak value of the impact of pollution emission $y(t)$ on energy saving and emission reduction $x(t)$ \\
\hline$F$ & The peak value of pollution emission $y(t)$ in an economic cycle \\
\hline$E$ & The peak value of economic growth $z(t)$ in an economic cycle \\
\hline$N$ & The peak value of the impact of energy saving and emission reduction $x(t)$ on economic growth $z(t)$ in an economic cycle \\
\hline$H$ & The peak value of the impact of economic growth $z(t)$ on environmental quality $w(t)$ in an economic cycle \\
\hline$P$ & The maximum amount of pollution that can be contained by the ecological environment \\
\hline
\end{tabular}

$0<c_{2}<0.0575$, that equilibrium point $O(0,0,0,0)$ is unstable.

Now, bring the parameter values set above to system (1). By calculation, we get the equilibrium points: $S_{1}(-1.4149,0.534,3.7951,-0.5030), \quad S_{2}(1.35,0.5868$, $1.4901,0.2367), \quad S_{3}(1.0838,0.6617,0.7819,0.2)$, $S_{4}(0.8185,2.5042,0.7327,-0.4697), \quad$ and $S_{5}(1.2523,2.5109,2.2876,-1.0085)$. A similar approach shows the eigenvalue of the equilibrium point $S_{1}$ : $\lambda_{1}=-0.7309, \lambda_{2}=-0.4548$, and $\lambda_{3,4}=0.2696 \pm 0.2758 i$; the eigenvalue of the equilibrium point $S_{2}: \lambda_{1}=-0.0314$, $\lambda_{2}=0.0665$, and $\lambda_{3,4}=-0.0783 \pm 0.1974 i$; the eigenvalue of the equilibrium point $S_{3}: \lambda_{1}=-0.5057, \lambda_{2}=-0.0189$, and $\lambda_{3,4}=0.2068 \pm 0.3074 i$; the eigenvalue of the equilibrium point $S_{4}: \lambda_{1}=0.0232, \quad \lambda_{2}=0.1221, \quad$ and $\lambda_{3,4}=-0.1191 \pm 0.0801 i$; the eigenvalue of the equilibrium point $S_{5}$ : $\lambda_{1}=-0.3009, \quad \lambda_{2}=0.1127, \quad$ and $\lambda_{3,4}=0.0519 \pm 0.1578 i$. At the equilibrium point $\left.S_{1}(-1.4149,0.534,3.7951,-0.5030) 3.7951,-0.5030\right), x(t)$ is negative and energy intensity is about 0.14 . Environmental quality $w(t)$ has reached dynamic equilibrium or gradually improved, which is an ideal state:

$$
\begin{aligned}
\nabla V= & \frac{\partial \dot{x}}{\partial x}+\frac{\partial \dot{y}}{\partial y}+\frac{\partial \dot{z}}{\partial z}+\frac{\partial \dot{w}}{\partial w}=\left(-1+\frac{y}{M}\right) a_{1}+\frac{(F-2 y) b_{2}}{F} \\
& -c_{3}+\left(-1+\frac{y}{P}\right) d_{4} \\
= & b_{2}-a_{1}-c_{3}-d_{4}+y\left(\frac{a_{1}}{M}-\frac{2 b_{2}}{F}+\frac{d_{4}}{P}\right)
\end{aligned}
$$

When $\quad\left(a_{1} / M\right)-\left(2 b_{2} / F\right)+\left(d_{4} / P\right)=0 \quad$ and $b_{2}-a_{1}-c_{3}-d_{4}<0$, system (1) is dissipative.
2.2. System Simulation Analysis. Numerical simulation analysis of the system allows us to more intuitively see the complex dynamic behavior of the system, which plays a very important role in the evolution and stability of the research system. Next, we will carry out dynamic simulation analysis of the $3 \mathrm{E}$ system under the energy reduction constraint and select the initial value of the system $[0.015,0.758,1.83,1.5]$.

As can be seen from Figure 1, the evolution trajectory of the system (1) enters an irregular chaotic state, and the shape of the three-dimensional attractor diagram composed of different parameters is also different.

In addition, Figure 2 gives system (1) mixed phase diagram of a two-dimensional plane in different sections. It can be seen from Figure 2 that the irregular evolution trajectories of system (1) under different cross sections are not the same, which also shows that the chaotic motion is irregular and disordered. The generation of mixed behavior in the $3 \mathrm{E}$ system will have a great impact on the stability of the system and also cause problems in the normal operation of the system. The time series diagram of system (1) $(x(t)$, $y(t), z(t)$, and $w(t))$ is given in Figure 3 .

Figure 4 shows bifurcation diagram and corresponding Lyapunov exponential diagram of the variable $c_{2} \in[0.006,0.014]$ change of the four-dimensional system (1). From Figure 4, we find that the four-dimensional system (1) has very complex dynamic behavior. As we all know, the Lyapunov exponential is generally used to determine whether the system is stable. If the maximum Lyapunov exponent of the system is greater than 0 , it can be explained that the system produces mixed chaotic behavior, which is a full manifestation of unstable evolution. In this study, the degree of complexity of the four-dimensional $3 \mathrm{E}$ systems under the constraints of energy reduction is self-evident. If the maximum Lyapunov exponent of the system is greater 


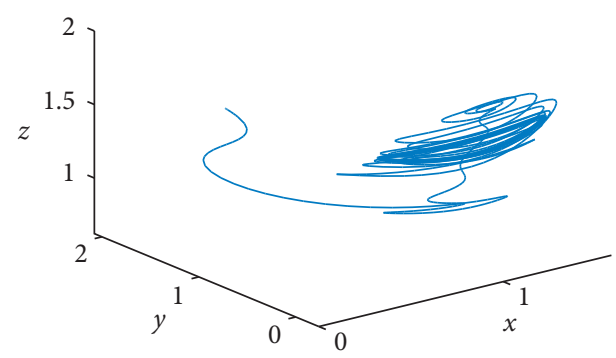

(a)

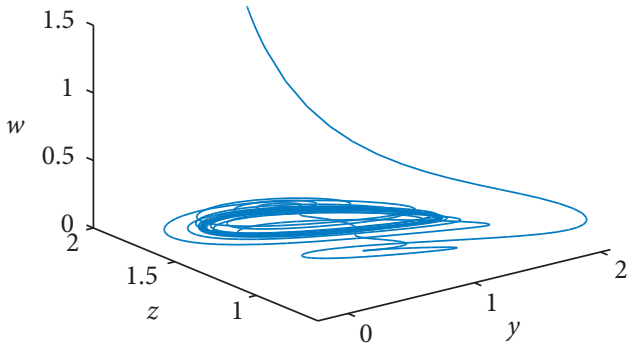

(c)

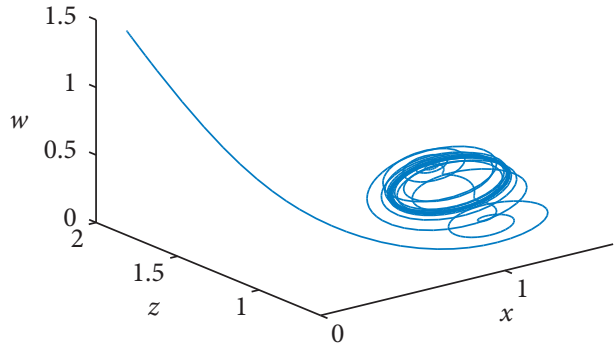

(b)

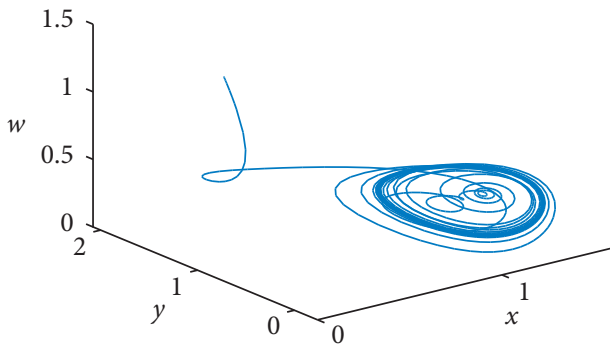

(d)

FIgURE 1: Three-dimensional spatial chaotic attractor phase diagram of system (1).

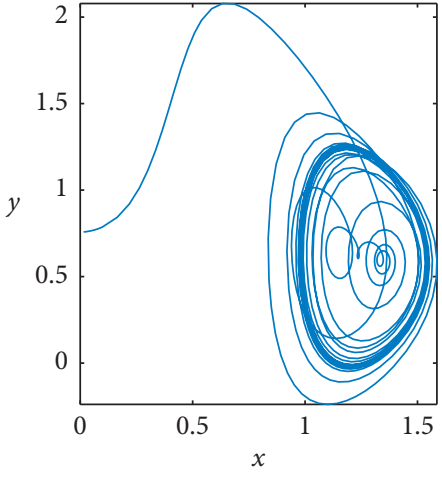

(a)

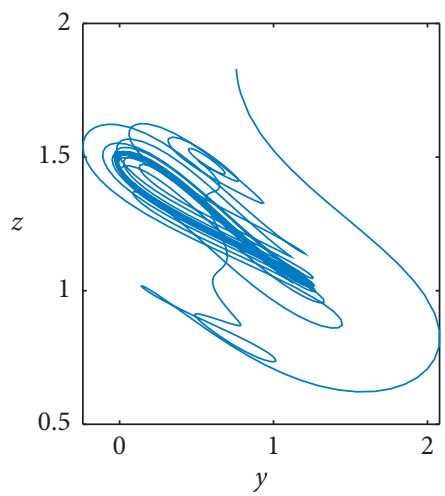

(d)

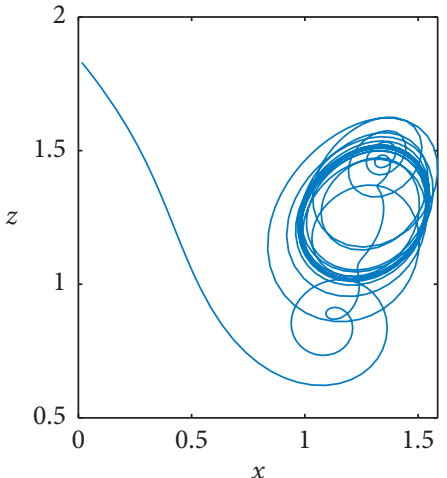

(b)

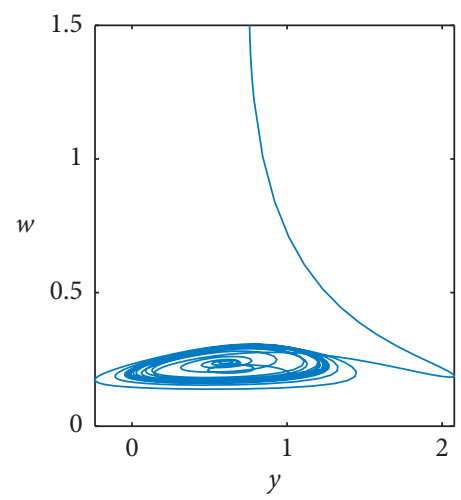

(e)

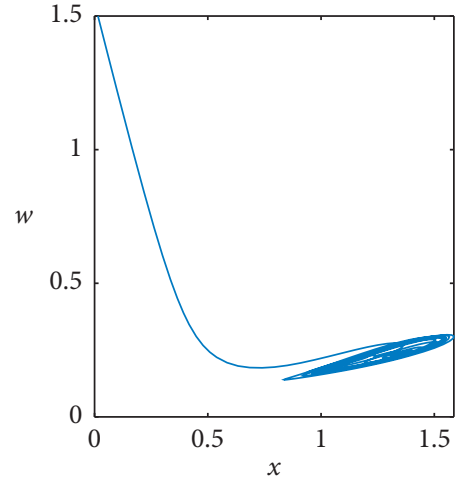

(c)

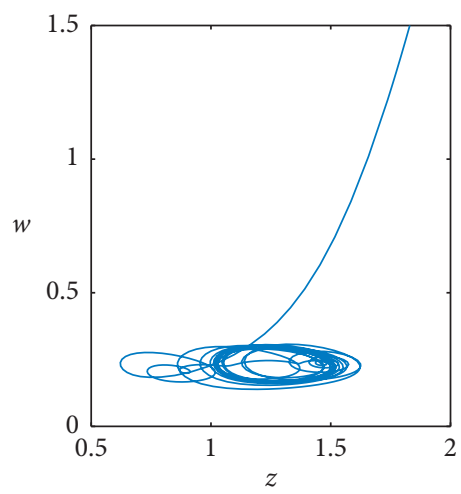

(f)

Figure 2: Two-dimensional plane chaotic attractor phase diagram of system (1).

than or equal to zero, we can determine the occurrence of bifurcation in the four-dimensional system. Behavior is more likely to develop into a chaotic trend.
Impact of initial state on the evolution trend of the complex four-dimensional dynamical system (1): Figure 5 shows the sensitive dependence of complex four-dimensional 

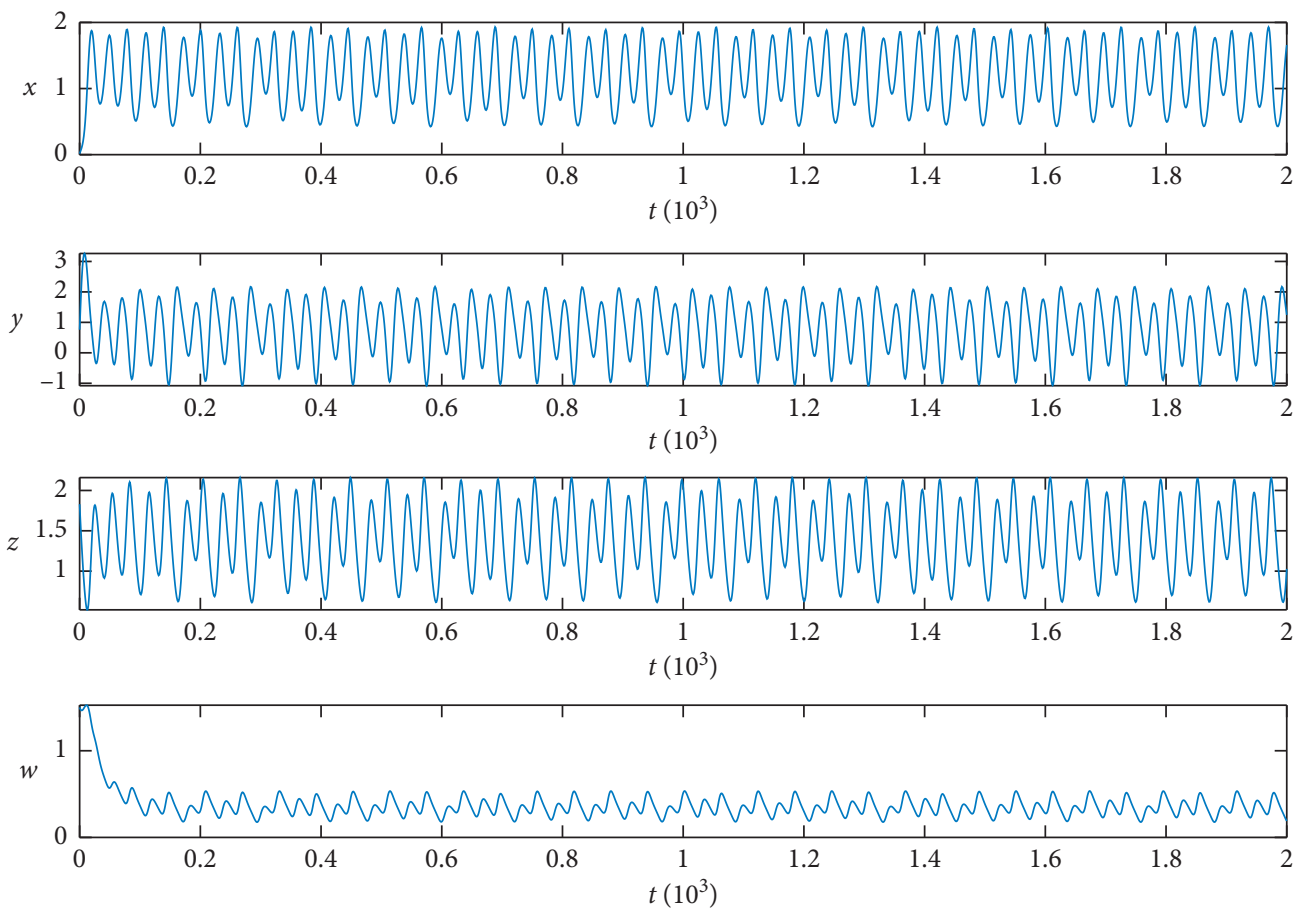

FIGURE 3: System (1) time sequences diagram.

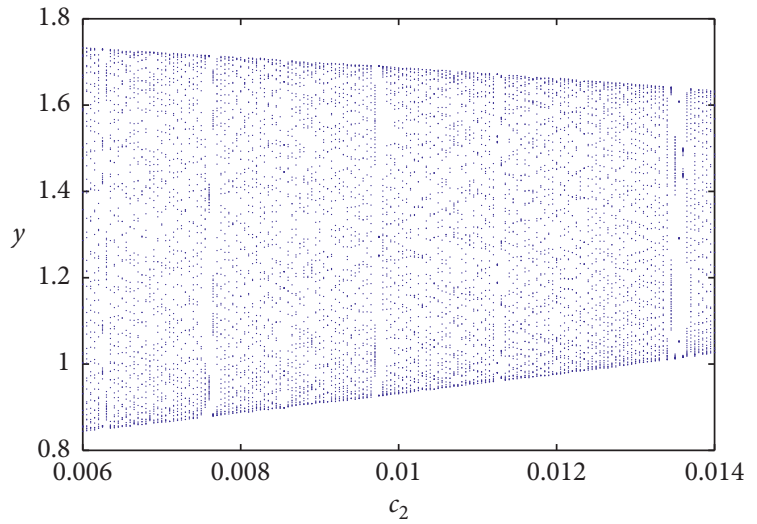

(a)

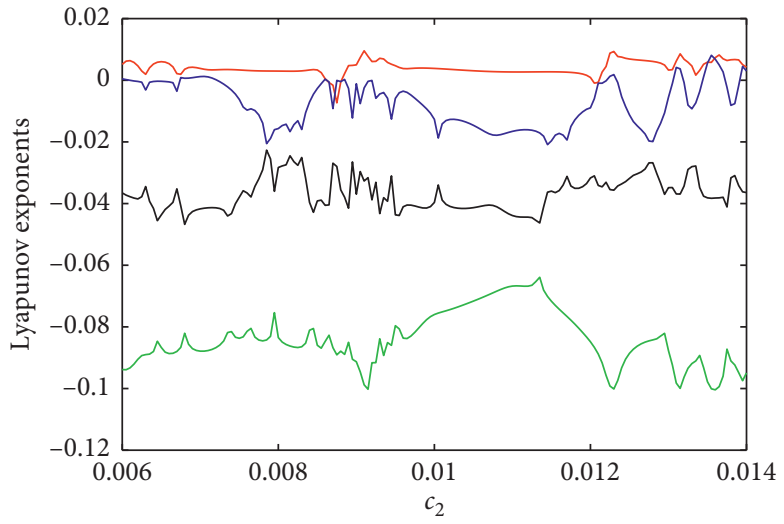

(b)

FIgURE 4: With $c_{2} \in[0.006,0.014]$ change system (1): (a) bifurcation diagram; (b) Lyapunov exponential diagram of corresponding (a).

system (1) on initial conditions. The sensitivity of system (when losing stability) with $(x, y, z, w)=(0.015,0.758$, 1.83.1.5), $\quad\left(x_{1}, y, z, w\right)=(0.014,0.758, \quad 1.83 .1 .5), \quad$ and $\left(x_{2}, y, z, w\right)=(0.016,0.758,1.83 .1 .5)$ and a small change in the initial conditions may cause a large change in the whole four-dimensional system, which indicates that the system is sensitive to the initial state. From Figure 5, we can also know that the initial values vary greatly in the trajectories of the deviated system (1). Although the initial states are indistinguishable, the initial values will be quickly established after several iterations, which is also an important symbol of chaotic motion.

\section{System Parameter Identification}

3.1. Data Gathering. On the basis of complex interactions, a four-dimensional dynamic system that integrates, restricts, and promotes energy conservation, energy, economy, and environment is established. In this study, the determination of the parameters of the four-dimensional dynamic system is of great significance to the actual research. Because the environment, energy intensity, and economic growth are affected by the changes of these variables, based on the official statistics and measured data of the China Statistical Yearbook, genetic optimization of the optimized LM-BP neural network method 


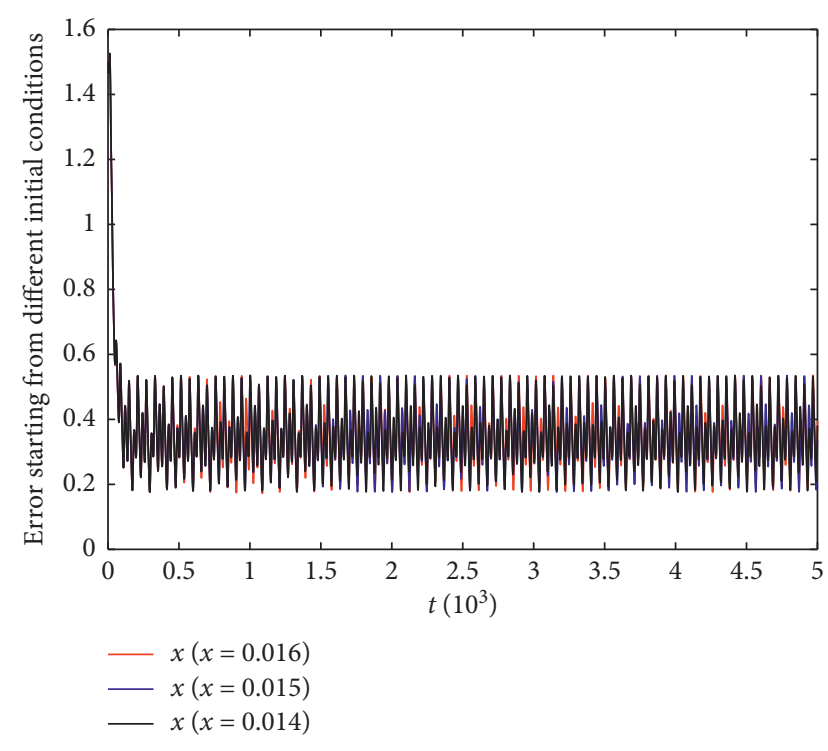

Figure 5: System (1) sensitivity analysis.

is used to obtain the actual parameters of the four-dimensional system, to further analyze the evolutionary relationship between energy consumption, energy, economic growth, and the environment of the $3 \mathrm{E}$ system.

In this paper, we mainly use the calculation method of energy reduction that is now common in the world to calculate the amount of skill emission reduction [18]. The principal component analysis method based on the covariance matrix is used to calculate the environmental quality index [1] to represent the data of the environmental change. Data on energy consumption and economic growth are mainly derived from China's official statistical yearbook. In addition, in order to make the environmental quality index positive during the research process, we also use the logarithmic logic model for data standardization. All the data in Table 2 is a standardized process based on the 1999 data. The final data is as follows.

3.2. Model Validation. The LM-BP neural network method optimized by genetic algorithm has a good application in the parameter identification of nonlinear systems [1], and it has good identification accuracy, which makes this method widely used in nonidentification of linear system parameters. After system (1) is discretized, the difference equation of the following form is obtained:

$$
\left\{\begin{array}{l}
x(k+1)=x(k)+T\left[a_{1} x(k)\left(\frac{y}{M-1}\right)-a_{2} y+a_{3} z+a_{4} w\right] \\
y(k+1)=y(k)+T\left[-b_{1} x+b_{2} y\left(\frac{1-y}{F}\right)+b_{3} z\left(\frac{1-z}{E}\right)-b_{4} w\right] \\
z(k+1)=z(k)+T\left[c_{1} x\left(\frac{x}{N-1}\right)-c_{2} y-c_{3} z-c_{4} w\right] \\
w(k+1)=w(k)+T\left[d_{1} x-d_{2} y+d_{3} z\left(\frac{1-z}{H}\right)+d_{4} w\left(\frac{y}{P-1}\right)\right] .
\end{array}\right.
$$

TABLE 2: Statistics on energy reduction, energy consumption, GDP, and environment in China.

\begin{tabular}{ccccc}
\hline Year & $x$ & $y$ & $z$ & $w$ \\
\hline 2000 & 1.9626 & 1.0455 & 1.1085 & 0.9837 \\
2001 & 3.6786 & 1.1066 & 1.2228 & 0.9595 \\
2002 & 2.2791 & 1.2064 & 1.3482 & 0.9347 \\
2003 & 1.2699 & 1.4020 & 1.5283 & 0.8747 \\
2004 & 2.3033 & 1.6382 & 1.8062 & 0.7741 \\
2005 & 1.9352 & 1.8594 & 2.0813 & 0.7242 \\
2006 & 2.0778 & 2.0380 & 2.4509 & 0.6403 \\
2007 & 3.9437 & 2.2156 & 3.0307 & 0.5455 \\
2008 & 6.5583 & 2.2808 & 3.5976 & 0.4752 \\
2009 & 3.2830 & 2.3912 & 3.8997 & 0.4061 \\
2010 & 3.3307 & 2.5656 & 4.6020 & 0.3693 \\
2011 & 3.6871 & 2.7534 & 5.4243 & 0.3565 \\
2012 & 4.0130 & 2.8608 & 6.0326 & 0.3210 \\
2013 & 3.9274 & 2.9659 & 6.6068 & 0.2817 \\
2014 & 4.2167 & 3.0292 & 7.2151 & 0.2575 \\
2015 & 4.2893 & 3.0583 & 7.6813 & 0.2322 \\
2016 & 4.5925 & 3.1004 & 8.2872 & 0.2159 \\
2017 & 4.6121 & 3.1942 & 9.2297 & 0.2147 \\
\hline
\end{tabular}

In this study, we used the former $n-1$ group of data as the input data of the LM-BP neural network optimized by the genetic algorithm and the post $n-1$ data as the output data of the LM-BP neural network optimized by the genetic algorithm. In addition, the data needs to be normalized in $\overline{x_{i}}=\left(x_{i}-x_{\min }\right) /\left(x_{\max }-x_{\min }\right)$ form. All other parameters will be set to random number and the identified error control $10^{-6}$. Finally, the identified system parametersare as shown in Table 3.

The data of 1980 is selected as the initial value of system $[0.00000085,0.658,1.73,1.1211]$, and the true validity of the identification parameters is further verified. The evolution trajectory of the system is shown in Figures 6 and 7. It can be seen from the phase diagram of the evolutionary trajectory of the system that the evolution trajectory of the system is multicycle and can always be in a stable mode. This explains the true effectiveness of the system from the side, which is also in line with the real situation.

\section{System Parameter Analysis}

In order to fully understand the stability of the above fourdimensional system (1), as well as the changes and impacts of energy intensity, how to effectively reduce energy intensity, stabilize economic development, improve the quality of ecological environment, and seek for high-quality, sustainable development models and strategies, and suggestions for the coordinated development of energy, economy, and environment, therefore, it is necessary to conduct an indepth analysis of some key parameters of the four-dimensional system (1).

In Figures 8(a) and 8(b), we can find that although increasing the investment in energy saving and emission reduction can effectively improve the environmental quality, the effect on reducing energy intensity is not obvious. Over time, the amplitudes of the evolutionary fluctuations of energy intensity and environmental quality oscillate around 


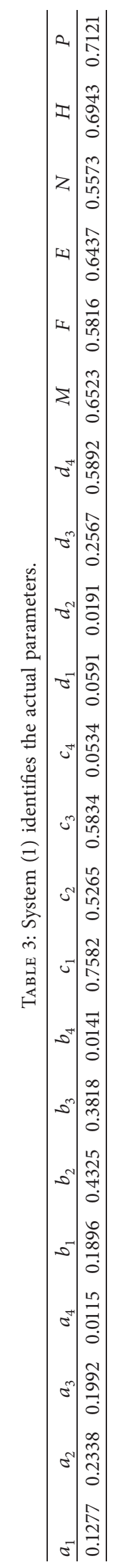




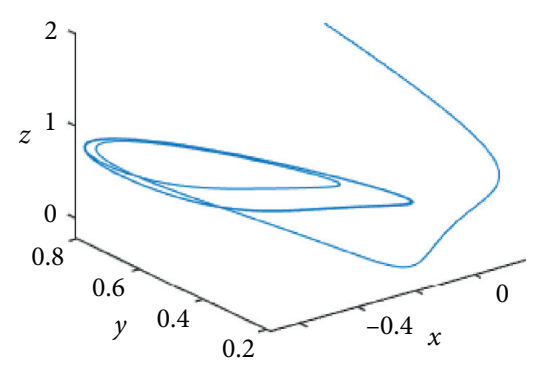

(a)

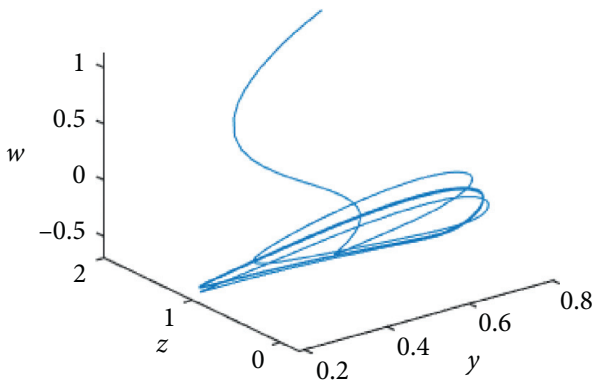

(c)

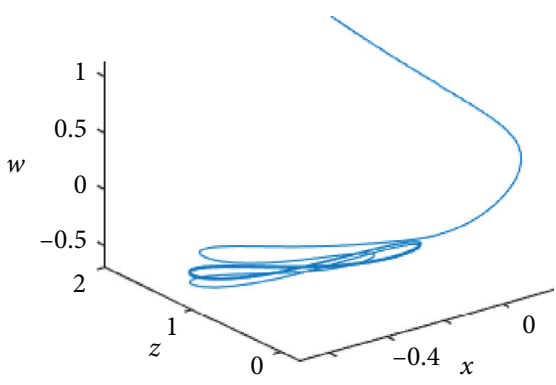

(b)

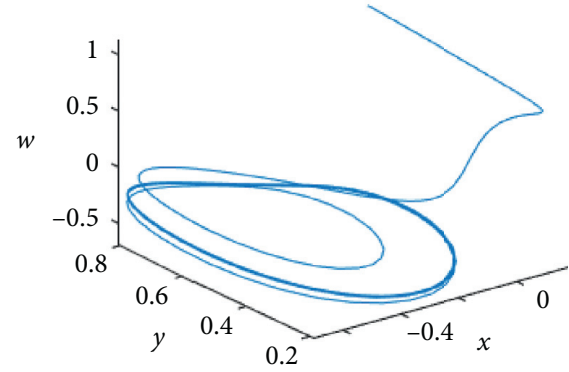

(d)

FIgURE 6: Three-dimensional spatial phase diagram of system (1) with identified parameters.

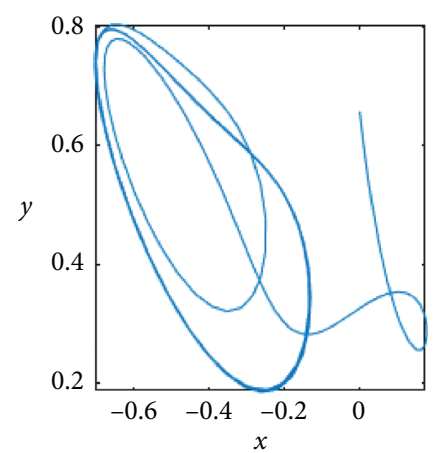

(a)

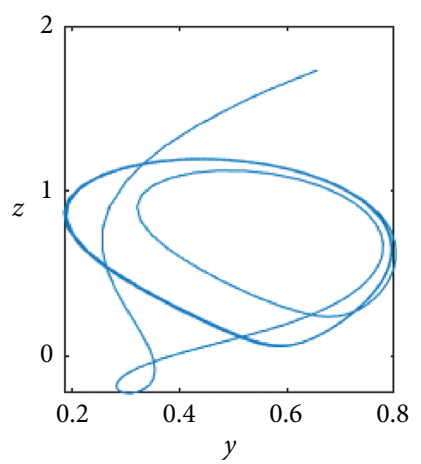

(d)

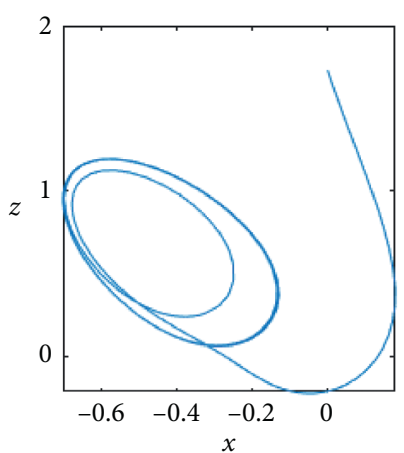

(b)

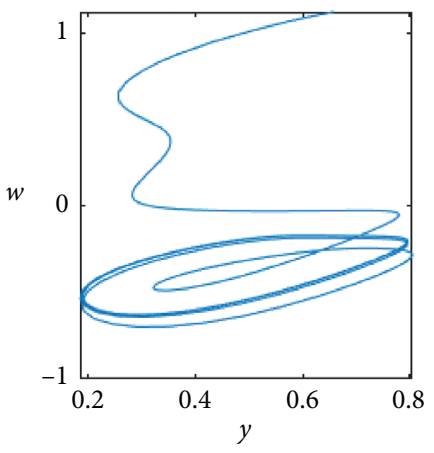

(e)

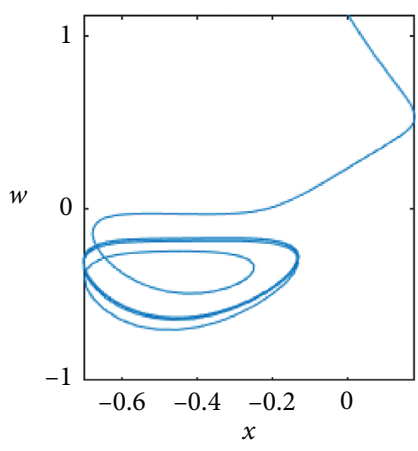

(c)

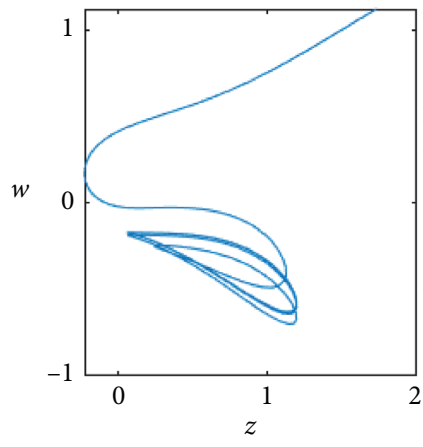

(f)

FIgURE 7: Two-dimensional plane phase diagram of system (1) with identified parameters.

a certain value. In a relatively short period of time, the improvement of environmental quality is also very obvious, but in the long run, the environment is still deteriorating with the decline in the discount rate of energy-saving and emission-reduction inputs. The oscillating amplitude of energy intensity will decrease significantly with the increase 


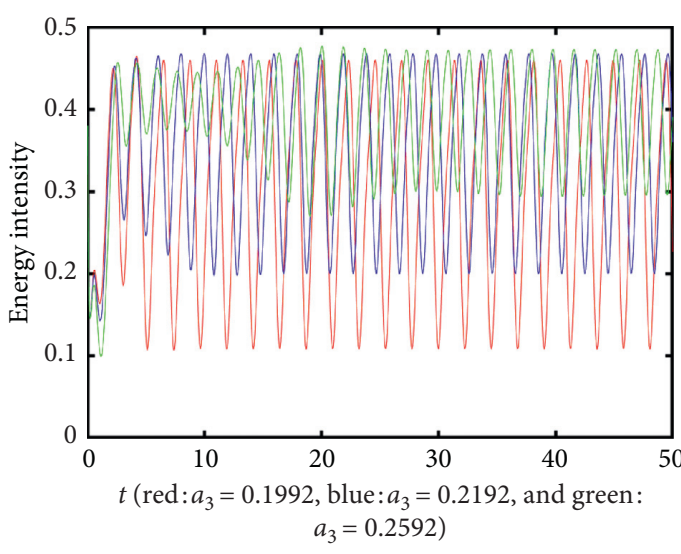

(a)

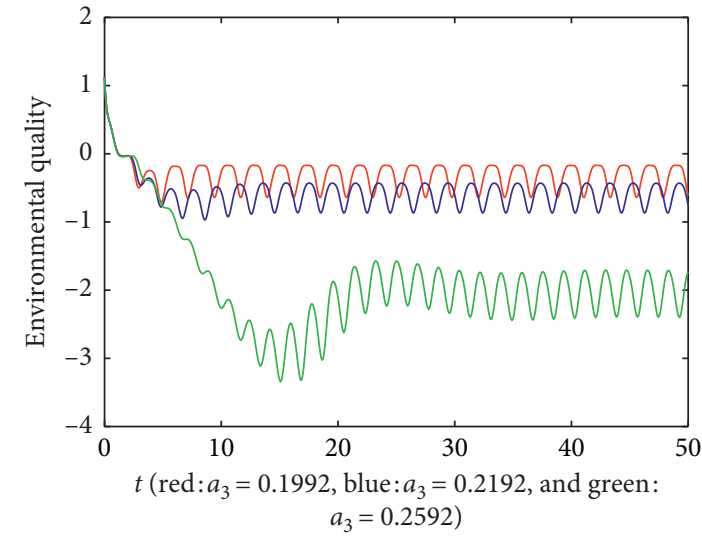

(b)

Figure 8: The parameters $a_{3}$ on the influence of system (1).

of energy-saving and emission-reduction input, but there is no obvious effect on the peak energy intensity. Therefore, it is not obvious that the effect of reducing the energy intensity and improving the stability of environmental quality by simply increasing the investment in energy saving and emission reduction is not obvious.

From Figures 9(a) and 9(b), we can find that when the peak value of pollution emissions $F=0.5816$, the evolution trajectories of energy intensity and environmental quality show fluctuations around a certain central value over time. This phenomenon will be very unfavorable to the improvement of environmental quality in controlling pollution emissions (i.e., the inability to effectively reflect the energy reduction policies); when $F=0.4816$, with the passage of time, energy intensity and environmental quality are still fluctuating up and down at a certain central value but will gradually shrink with the magnitude of evolutionary fluctuations, and the maximum peak of energy intensity is also significantly smaller than before. It also has a significant impact on the evolution of environmental quality. In the long run, the central value of the shock is decreasing, the amplitude of the shock is decreasing, and eventually it tends to be stable. After the pollution emission peak is lowered again $F=0.3816$, the energy intensity and environmental quality evolve to a stable value at a relatively fast rate, and the peak value of the energy intensity and the center value of the oscillation are reduced again before comparison. Therefore, it can be better explained that effective control of the peak arrival time of pollution emissions can be used as an important decision for pollution emission control and energy intensity reduction.

From Figure 9(b), we can also find that the advance of the peak of pollution emissions makes the environmental system take the risk ahead, and the threat level is greatly increased. The reason for this phenomenon is that the peak of pollution discharge exceeds the self-purification speed of the natural environment system during the self-circulation process, so that the accumulation of pollutants in the ecological environment system reaches the maximum capacity, and the self-purification ability of the environmental system is weakened. In a relatively short period of time, the ecological environment system is extremely deteriorated. Therefore, how to effectively and reasonably control the peak of pollution emission is very important for controlling the stability of $3 \mathrm{E}$ system and improving the environmental quality.

By comparing Figure 10(a), it can be found that, in the short term, the environmental capacity of the ecosystem has no significant effect on the stability of the evolution of the $3 \mathrm{E}$ system. As the environmental capacity decreases, over time, the evolution of environmental quality shows an upward trend of fluctuations and fluctuations around a certain central value; when the capacity of the ecosystem falls to the limit (i.e., the pollution effect exceeds the ecological environment), the system collapses (i.e., the ecological environment disappears, and the ecosystem can no longer rely on self-regulation to repair the ecological environment). As a result, this situation continues and the ecological environment is eventually sold out. It is confirmed that the ecological environment system has a certain bearing capacity, and the effect that the ecosystem will not be in operation or self-purification after the limit value can be exceeded is not significant.

From Figure 10(b), we can find that the effect of simply increasing the economic investment in the environment to improve the environmental quality is not obvious, it does not increase the economic investment as expected, and the environment can be effectively improved. From the evolutionary trajectory of the system, it can be seen that the evolutionary trajectory of the system revolves around central value fluctuation and oscillation amplitude over time. This phenomenon shows that the effects of economic input in the process of environmental governance are not significant enough. Therefore, in order to improve the quality of the ecological environment and promote the rapid development of the economy, we need more measures to use more means and technologies to promote stable economic growth and management of the ecological environment. It is necessary to correctly grasp the ecological environment protection and the relationship between economic developments, explore 


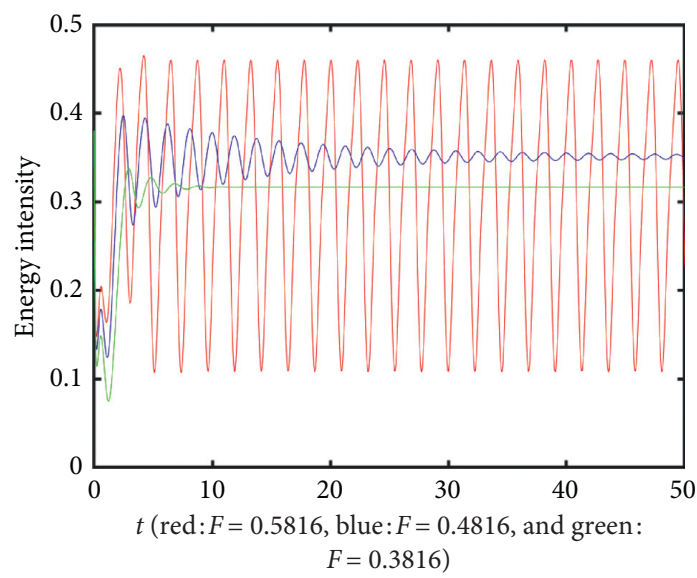

(a)

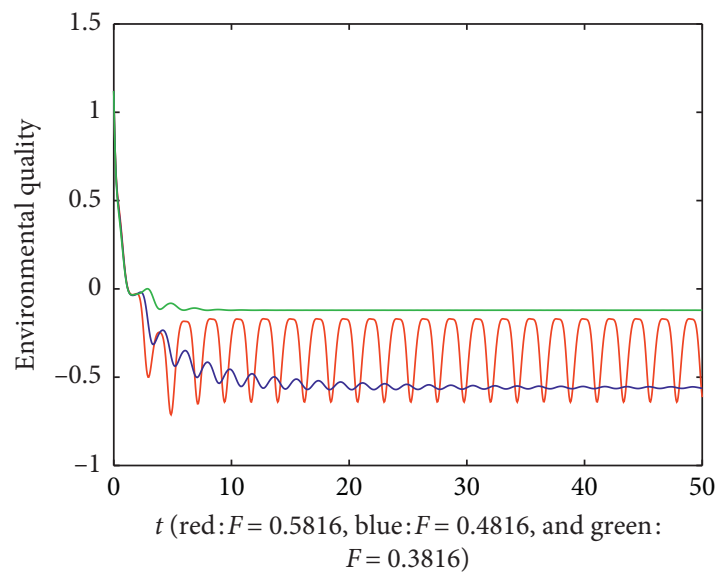

(b)

Figure 9: The parameters $F$ on the influence of system (1).

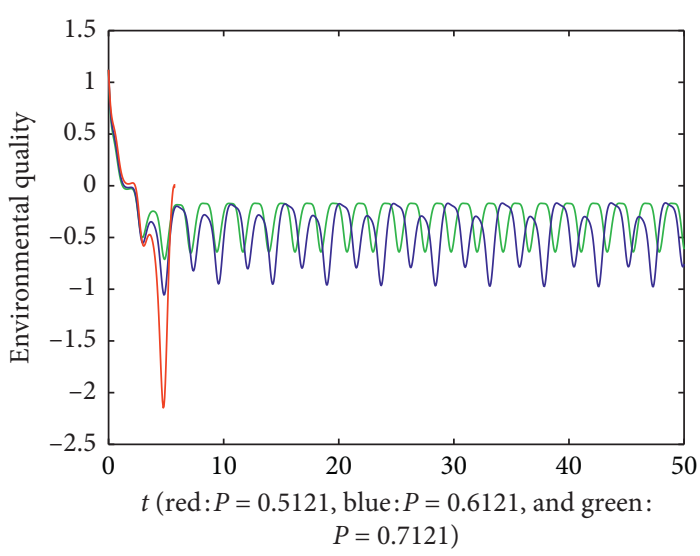

(a)

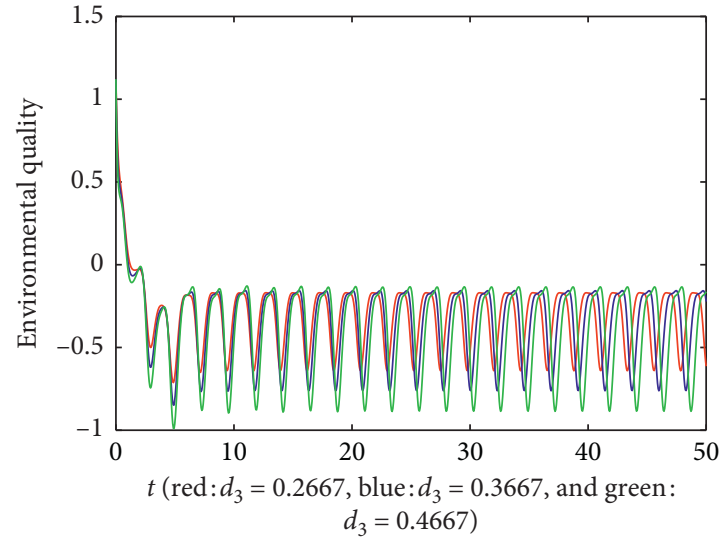

(b)

Figure 10: The different parameters $P$ and $d_{3}$ on the influence of system (1).

synergies to promote ecological priorities and green development new ideas, and ultimately achieve a "win-win" environment and economy.

\section{Conclusion}

In this study, the energy, economic, and environmental (3E) four-dimensional system model of energy conservation constraints was first established. The Bayesian estimation method is used to correct the environmental quality variables to obtain the environmental quality data needed for the research. In addition, based on the Chinese statistical yearbook data, the Levenberg-Marquardt BP neural network method optimized by genetic algorithm is used to energy, economy, and environment under energy conservation constraints. The parameters in the four-dimensional system model are effectively identified. Finally, the system science analysis theory and complex system dynamics theory are used to analyze the stability and complex dynamics of the model and explore the influence of some key parameters in the four-dimensional system on the evolution stability of the system. The main conclusions are as follows:

(1) Although increasing the investment in energy reduction can effectively improve the environmental quality; in a relatively short period of time, the improvement of environmental quality is also very obvious, but in the long run, the environment is still deteriorating with the decline in the discount rate of energy reduction inputs.

(2) It can be better explained that effective control of the peak arrival time of pollution emissions can be used as an important decision for pollution emission control and energy intensity reduction; therefore, how to effectively and reasonably control the peak of pollution emissions is of great significance for controlling the stability of energy, economy, and environment system under the constraint of energy 
reduction, regulating energy intensity, and improving environmental quality and sustainable development.

(3) As the environmental capacity decreases, over time, the evolution of environmental quality shows an upward trend of fluctuations and fluctuations around a certain central value; when the capacity of the ecosystem falls to the limit, the system collapses. In order to improve the quality of the ecological environment and promote the rapid development of the economy, we need more measures to use more means and technologies to promote stable economic growth and management of the ecological environment.

Therefore, it is necessary to correctly grasp the ecological environment protection and the relationship between economic developments and explore synergies to promote ecological priorities and green development new ideas.

\section{Data Availability}

The numerical simulations data used to support the findings of this study were supplied by the corresponding author under license and so cannot be made freely available. Requests for access to these data should be made to the corresponding author (e-mail address: 136901672@qq.com).

\section{Conflicts of Interest}

The authors declare no conflicts of interest.

\section{Acknowledgments}

This work was supported by the National Nature Science Foundation of China (no. 71974081), Humanities and Social Sciences Research Project of the Ministry of Education of China (17YJAZH035), the Philosophy and Social Science Fund for University of Jiangsu (no. 2019SJA1051), and Jiangsu University of Technology Talent Introduction Project (KYY18539).

\section{References}

[1] L. Zhao, C. Otoo, and A. Otoo, "Stability and complexity of a novel three-dimensional environmental quality dynamic evolution system," Complexity, vol. 2019, Article ID 3941920, 11 pages, 2019.

[2] G. Fang, L. Tian, M. Sun, and M. Fu, "Analysis and application of a novel three-dimensional energy-saving and emissionreduction dynamic evolution system," Energy, vol. 40, no. 1, pp. 291-299, 2012.

[3] R. K. Upadhyay, S. R. K. Iyengar, and V. Rai, "Stability and complexity in ecological systems," Chaos, Solitons \& Fractals, vol. 11, no. 4, pp. 533-542, 2000.

[4] J. Asafu-Adjaye, "The relationship between energy consumption, energy prices and economic growth: time series evidence from Asian developing countries," Energy Economics, vol. 22, no. 6, pp. 615-625, 2000.

[5] G. Hondroyiannis, S. Lolos, and E. Papapetrou, "Energy consumption and economic growth: assessing the evidence from Greece," Energy Economics, vol. 24, no. 4, pp. 319-336, 2002.

[6] S. Wang, J. Xu, and C. Qiu, "Bounds testing for energy consumption and environmental pollution," China Population, Resources and Environment, vol. 20, no. 4, pp. 69-73, 2010.

[7] L. I. Guozhang, J. Jiang, and C. Zhou, "Relation between total factor energy efficiency and environmental pollution," China Population, Resources and Environment, vol. 20, no. 4, pp. 50-56, 2010.

[8] R. López, "The environment as a factor of production: the effects of economic growth and trade liberalization," Journal of Environmental Economics and Management, vol. 27, no. 2, pp. 163-184, 1994.

[9] A. Grainger, "The forest transition: an alternative approach," Area, vol. 3, pp. 242-251, 1998.

[10] M. Shahbaz, N. Khraief, G. S. Uddin, and I. Ozturk, "Environmental Kuznets curve in an open economy: a bounds testing and causality analysis for Tunisia," Renewable \& Sustainable Energy Reviews, vol. 34, pp. 325-336, 2014.

[11] J. Andreoni and A. Levinson, "The simple analytics of the environmental Kuznets curve," Journal of Public Economics, vol. 80, no. 2, pp. 269-286, 2001.

[12] E. Magnani, "The Environmental Kuznets Curve: development path or policy result?" Environmental Modelling \& Software, vol. 16, no. 2, pp. 157-165, 2001.

[13] A. K. Bello and O. M. Abimbola, "Does the level of economic growth influence environmental quality in Nigeria: a test of environmental Kuznets curve (EKC) hypothesis?" Pakistan Journal of Social Sciences, vol. 7, no. 4, pp. 325-329, 2010.

[14] C. Liu, D. Duan, R. Yu et al., "Spatial-temporal structure of coupling of the economy resources-environment system in Wuhan metropolitan area," China Population, Resources and Environment, vol. 24, no. 5, pp. 145-152, 2014.

[15] Z. Guo, Y. Zheng, and X. Zhang, "Analysis of the energyenvironment-economy system in China based on dynamic CGE model," Journal of Systems Engineering, vol. 29, no. 5, pp. 581-591, 2014.

[16] L. Zheng and Q. Zhu, "Vertical technological progress, industrial structure change and sustainable economic growth under energy and environment constraints," Journal of Finance and Economics, vol. 7, pp. 49-60, 2013.

[17] Z. L. Zhang, B. Xue, X. P. Chen, and C. Y. Lu, "Evolutionary mechanism analysis of energy-economy-environment system in China: based on Haken model," Ecological Economy (Chinese Version), vol. 31, no. 1, pp. 14-17, 2015.

[18] Y.-M. Wei, R. Zeng, and Y. Fan, "A multi objective goal programming model for Beijing's coordination development of population, resources, environment and economy," System Engineering-Theory and Practice, vol. 22, no. 2, pp. 74-83, 2002.

[19] A. Löschel and V. M. Otto, "Technological uncertainty and cost effectiveness of $\mathrm{CO}_{2}$ emission reduction," Energy Economics, vol. 31, no. 31, pp. S4-S17, 2009.

[20] C. Erdmenger, H. Lehmann, K. Müschen, J. Tambke, S. Mayr, and $\mathrm{K}$. Kuhnhenn, "A climate protection stategy for Germany-40\% reduction of $\mathrm{CO}_{2}$ emission by 2020 compared to 1990," Energy Policy, vol. 37, pp. 158-165, 2009.

[21] Y. Xu and T. Masui, "Local air pollutant emission reduction and ancillary carbon benefits of $\mathrm{SO}_{2}$ control policies: application of AIM/CGE model to China," European Journal of Operational Research, vol. 198, no. 1, pp. 315-325, 2009.

[22] J. M. Cullende and J. M. Allood, "The efficient use of energy: tracing the global flow of energy from fuel to service," Energy Policy, vol. 38, no. 1, pp. 75-81, 2010. 
[23] M. Prasad and S. Munch, "State-level renewable electricity policies and reductions in carbon emissions," Energy Policy, vol. 45, no. 45, pp. 237-242, 2012.

[24] G. Fang, L. Tian, M. Fu, and M. Sun, "The impacts of carbon tax on energy intensity and economic growth - a dynamic evolution analysis on the case of China," Applied Energy, vol. 110, pp. 17-28, 2013.

[25] G. Fang, L. Tian, M. Fu, M. Sun, Y. He, and L. Lu, "How to promote the development of energy-saving and emissionreduction with changing economic growth rate-a case study of China," Energy, vol. 143, no. 143, pp. 732-745, 2018.

[26] G. Fang, L. Tian, M. Fu et al., "The effect of energy construction adjustment on the dynamical evolution of energysaving and emission-reduction system in China," Applied Energy, vol. 196, pp. 180-189, 2017.

[27] G. Fang, L. Tian, M. Fu, M. Sun, R. Du, and M. Liu, "Investigating carbon tax pilot in YRD urban agglomerationsAnalysis of a novel ESER system with carbon tax constraints and its application," Applied Energy, vol. 194, pp. 635-647, 2017.

[28] X. Li, J. Du, and H. Long, "A comparative study of Chinese and foreign green development from the perspective of mapping knowledge domains," Sustainability, vol. 10, no. 12, p. 4357,2018 .

[29] X. Fan, Y. Zhang, and J. Yin, "Evolutionary analysis of a threedimensional carbon price dynamic system," Sustainability, vol. 11, no. 1, p. 116, 2019.

[30] J.-Z. Wang, J.-J. Wang, Z.-G. Zhang, and S.-P. Guo, "Forecasting stock indices with back propagation neural network," Expert Systems with Applications, vol. 38, no. 11, pp. 1434614355, 2011.

[31] M. A. Boyacioglu and D. Avci, "An adaptive network-based fuzzy inference system (ANFIS) for the prediction of stock market return: the case of the istanbul stock exchange," Expert Systems with Applications, vol. 37, no. 12, pp. 7908-7912, 2010.

[32] C.-H. Cheng, T.-L. Chen, and L.-Y. Wei, "A hybrid model based on rough sets theory and genetic algorithms for stock price forecasting," Information Sciences, vol. 180, no. 9, pp. 1610-1629, 2010.

[33] E. Hadavandi, H. Shavandi, and A. Ghanbari, "Integration of genetic fuzzy systems and artificial neural networks for stock price forecasting," Knowledge-Based Systems, vol. 23, no. 8, pp. 800-808, 2010.

[34] A. Bagheri, H. Mohammadi Peyhani, and M. Akbari, "Financial forecasting using ANFIS networks with quantumbehaved particle swarm optimization," Expert Systems with Applications, vol. 41, no. 14, pp. 6235-6250, 2014.

[35] X. Liu and X. Ma, "Based on BP neural network stock prediction," Journal of Curriculum and Teaching, vol. 1, no. 1, pp. 45-50, 2012.

[36] A. S. Babu and S. K. Reddy, "Exchange Rate Forecasting using ARIMA, neural network and fuzzy neuron," Journal of Stock \& Forex Trading, vol. 4, no. 3, pp. 1-5, 2015.

[37] A. Murkute and T. Sarode, "Forecasting market price of stock using artificial neural network," International Journal of Computer Applications, vol. 124, no. 12, pp. 11-15, 2015.

[38] Q. Ye and L. Wei, "The prediction of stock price based on improved wavelet neural network," Open Journal of Applied Sciences, vol. 5, no. 4, pp. 115-120, 2015.

[39] L. Zhang, F. Wang, B. Xu, W. Chi, Q. Wang, and T. Sun, "Prediction of stock prices based on LM-BP neural network and the estimation of overfitting point by RDCI," Neural Computing and Applications, vol. 30, no. 5, pp. 1425-1444, 2018.
[40] M. Marzouk and S. Azab, "Environmental and economic impact assessment of construction and demolition waste disposal using system dynamics," Resources, Conservation and Recycling, vol. 82, pp. 41-49, 2014.

[41] D. H. Meadows, J. Randers, and D. L. Meadows, The Limits to Growth: The 30-Year Update, Chelsea Green Pub, White River Junction, VT, USA, 2004.

[42] P. P.-J. Yang and O. B. Lay, "Applying ecosystem concepts to the planning of industrial areas:a case study of Singapore's Jurong Island," Journal of Cleaner Production, vol. 12, no. 8-10, pp. 1011-1023, 2004.

[43] Y. Fang, R. P. Côté, and R. Qin, "Industrial sustainability in China: practice and prospects for eco-industrial development," Journal of Environmental Management, vol. 83, no. 3, pp. 315-328, 2007.

[44] D. Guan, W. Gao, W. Su, H. Li, and K. Hokao, "Modeling and dynamic assessment of urban economy-resource-environment system with a coupled system dynamics- geographic information system model," Ecological Indicators, vol. 11, no. 5, pp. 1333-1344, 2011.

[45] S. F. Zhan, X. C. Zhang, C. Ma, and W. P. Chen, "Dynamic modelling for ecological and economic sustainability in a rapid urbanizing region," Procedia Environmental Sciences, vol. 13, pp. 242-251, 2012.

[46] I. Musu and M. Lines, "Endogenous growth and environmental preservation," "Endogenous growth and environmental preservation," in Environmental Economics: Proceeding of European Economic Association at Oxford, G. Boero and A. Silberston, Eds., St Martins Press, London, UK, 1995.

[47] D. Fullerton and S. Kim, "Environmental investment and policy with dissortional taxes and endogenous growth," Journal of Environmental Economics and Management, vol. 56, no. 2, pp. 141-154, 2008.

[48] J.-h. Chen, C. Lai, and J. Y. shieh, "Anticipated environment policy and transitional dynamics in endogenous growth model," Environmental and Resource Economics, vol. 25, no. 2, pp. 233-254, 2003. 